\title{
Editorial \\ On the Need for Better Exposure Assessment for Air Pollution with High Spatial and Temporal Variation
}

\author{
Doug Brugge ${ }^{1,2}$ \\ 1 Department of Community Medicine and Health Care, University of Connecticut School of Medicine, \\ 263 Farmington Ave., Farmington, CT 06030, USA; brugge@uchc.edu \\ 2 Department of Public Health and Community Medicine, Tufts University School of Medicine, 136 Harrison \\ Avenue, Boston, MA 02111, USA
}

Received: 5 May 2019; Accepted: 6 May 2019; Published: 7 May 2019

check for updates

The mainstay of air pollution health research has been fine particulate matter pollution $\left(\mathrm{PM}_{2.5}\right.$; aerodynamic diameter $<2.5$ microns). $\mathrm{PM}_{2.5}$ is an appealing pollutant to study because its concentration tends to vary only slightly across relatively large geographic areas, such as a metropolitan region. Because of this, it is expected that there will be small exposure errors from assigning city-wide levels or interpolating between a few or several fixed site monitors spread over a city or region. Recently, satellite data has added another means to assess $\mathrm{PM}_{2.5}$ levels at resolutions of a square kilometer where there are few or no ground level monitors. These approaches have been quite successful at establishing $\mathrm{PM}_{2.5}$ as one of the top ten public health problems in the world [1].

However, other pollutants are not as well behaved as $\mathrm{PM}_{2.5}$. In particular, some pollutants, such as ultrafine particles (UFPs; $<0.1$ microns), course PM (2.5-10 microns), black carbon (BC), and oxides of nitrogen (which are gasses) vary substantially over short distances (tens of meters) and in time (hourly) [2,3]. Because these pollutants are elevated near highways and major roadways, there is substantial literature using proximity to these sources as surrogates for exposure [4].

However, there are other possible explanations for health effects based on proximity, including elevated traffic noise and lower socioeconomic status (SES) next to busy roadways [5]. In addition, proximity does not help with separating out the effects of different air pollutants in the complex mix created by motor vehicles. An important distinction, for example, is gasses vs. particles [6]. Thus, in order to inform policy in competent and accurate ways, there is a need for epidemiology studies that accurately assign exposure to locally elevated and highly variable pollutants from traffic.

The temporal and spatial variation of these pollutants is compounded by the mobility of people. Most individuals do not stay at home all day, so assigning their exposure based only on their home address will introduce error [7]. It is also potentially problematic to assume that ambient levels of pollution outside the home are the same as those indoors, where most people spend most of their time while at home [8]. Of course, this problem also applies to $\mathrm{PM}_{2.5}$, but the entry of pollutants has been shown to vary based on their own properties as well as building characteristics [9].

For the sake of illustration, let us consider two individuals living next to a freeway. One might be retired and spend most of their day indoors at home with brief trips out for errands midday when traffic is not as bad as it would be at rush hour. Their home might have no mechanical air handling system or air filtration. The other might work at a job $8 \mathrm{~h}$ per day at a distance that requires commuting on a highway (high exposure) to an office that is not near traffic and that has excellent ventilation systems that reduce exposure further. Ambient air pollution levels at the home might be reasonably good for the former and quite erroneous for the latter.

A daunting challenge for environmental exposure assessment and epidemiology is to find ways to reduce exposure error and improve confidence in health outcome associations for near traffic pollutants. The projects that I have participated in and helped lead under the umbrella of the Community 
Assessment of Freeway Exposure and Health (CAFEH: https://sites.tufts.edu/cafeh/) have focused on one of these pollutants, ultrafine particles or UFPs, in the Boston, MA, USA, area. I believe that our attempts to grapple with this problem, while not solving it, point to some important lessons.

The first lesson that I would point to is the need for ambient models of near highway pollutants that have fine grain temporal and spatial resolution. We have produced models using either mobile monitoring alone or with stationary fixed site monitoring to improve temporal prediction $[10,11]$. These models were at hourly resolution for a year with $20 \mathrm{~m}$ spatial resolution. We lost predictive power relative to models that produce only annual averages, but gained the ability to consider exposure based on time activity patterns of participants in our studies.

The second lesson is that address matching is insufficient because it can contain errors of up to $100 \mathrm{~m}$, which is a large distance relative to the distances at which UFPs vary. One reason for this is that large multifamily developments can have a single address for apartments that extends over a block or more. In our first study, we resorted to positioning each address on an ortho map, including placing the participant within their apartment inside a multifamily building [7].

Third, we have monitored indoor-outdoor concentrations of UFPs in a subset of homes in our study as well as homes in a second (related) study [12,13]. The evidence from this work suggests that in the absence of forced air systems or free standing filters, UFPs infiltrate homes relatively well. This is likely because the homes in our study populations often have windows open and building envelopes that are relatively leaky even when windows are closed. Different populations, for example, people living in modern multifamily buildings with central ventilation, could have very different indoor concentrations compared to outdoor concentrations.

Fourth, adjusting exposure for participant time activity, as per the two hypothetical, but realistic, examples given above, changed assigned exposure for many participants. Of note, many near-highway residents were assigned lower exposures because their work took them away from the highway to less polluted areas for large parts of the day. We think these adjustments were an improvement in exposure assignment because exposure-response relationships became stronger and more monotonic after adjustment [14].

A final substantial factor to emerge from our analyses was that adjusting for confounding had an appreciable effect on the associations we observed. Body mass index was a leading (negative) confounder, as was race. We found that immigrants from East Asia, who were a large subpopulation in our sample, had much lower inflammatory responses to UFP exposure than the rest of our study population. Without making the adjustments just described, we would not have seen associations [15].

In addition to these primary lessons, we also explored some other factors that could affect exposure assignment and error. One was vertical dispersion of UFPs. We measured concentrations vertically from a tower near one of our neighborhoods and produced evidence that levels did not decline up to the fourth story or so and, accordingly, recruited only below this level [16]. We also used estimated respiratory rate to adjust exposure and have attempted to validate the calculated respiration rates with empirical data [17].

Despite our considerable attention to exposure error, we believe that substantial error remains. We are also unable, at this time, to extend these methods to large cohort studies. The reason for this is that the fine grain ambient models of UFP concentration do not transfer well from one geographic area to another [10]. Conducting the level of mobile and fixed site monitoring that we used for our models across large geographic regions, such as would be the case for most larger cohorts, would require unreasonable time and resources.

Most of the emerging UFP long-term exposure epidemiology uses annual averages for exposure [18]. This certainly has some advantages. For example, it has allowed other research teams to assign exposure to much larger populations than ours, potentially increasing statistical power. However, we suspect annual average exposures that are not adjusted for the factors we identified result in error that biases associations toward the null and contributes to small effect estimates that fall short of statistical significance. 
The strategy of increasing power through larger sample sizes and of improving fine grain exposure assessment could, potentially, be complimentary. Presumably, as one increases sample size and loses exposure accuracy, one is gaining statistical power. Perhaps there is a "sweet spot" at which one could maximize the benefits of statistical power while minimizing exposure error using at least some of the techniques we have employed.

This is an area ripe for research innovation with the potential reward of informing policy development. UFPs were, for the first time this year, included as likely to be causally related to health (neurological) in the US Environmental Protection Agency's Integrated Health Assessment for Particulate Matter [19]. Their inclusion, however, was based on controlled exposure animal and human toxicological studies, further emphasizing the need for definitive epidemiology studies to complement the work with animals.

Acknowledgments: The author would like to thank Wig Zamore for helpful comments on a draft of this editorial and would also like to thank Lisa Cook for assistance preparing the manuscript. Doug Brugge was supported by NIEHS (ES026980).

Conflicts of Interest: The authors declare no conflicts of interest.

\section{References}

1. Lim, S.S.; Vos, T.; Flaxman, A.D.; Danaei, G.; Shibuya, K.; Adair-Rohani, H.; Amann, M.; Anderson, H.R.; Andrews, K.G.; Aryee, M.; et al. A comparative risk assessment of burden of disease and injury attributable to 67 risk factors and risk factor clusters in 21 regions, 1990-2010: A systematic analysis for the Global Burden of Disease Study 2010. Lancet 2012, 380, 2224-2260. [CrossRef]

2. Karner, A.A.; Eisinger, D.S.; Niemeier, D.A. Near-roadway air quality: Synthesizing the findings from real-world data. Environ. Sci. Technol. 2010, 44, 5334-5344. [CrossRef]

3. Durant, J.L.; Ash, C.A.; Wood, E.C.; Herndon, S.C.; Jayne, J.T.; Knighton, W.B.; Canagaratna, M.R.; Trull, J.B.; Brugge, D.; Zamore, W.; et al. Short-term variation in near-highway air pollutant gradients on a winter morning. Atmos. Chem. Phys. 2010, 10, 5599-5626. [CrossRef] [PubMed]

4. Health Effects Institute. Traffic-Related Air Pollution: A Critical Review of the Literature on Emissions, Exposure, and Health Effects; Health Effects Institute: Boston, MA, USA, 2010.

5. Leaffer, D.; Wolfe, C.; Doroff, S.; Gute, D.; Wang, G.; Ryan, P. Wearable Ultrafine Particle and Noise Monitoring Sensors Jointly Measure Personal Co-Exposures in a Pediatric Population. Int. J. Environ. Res. Public Health 2019, 16, 308. [CrossRef] [PubMed]

6. Brugge, D.; Durant, J.L.; Rioux, C. Near-highway pollutants in motor vehicle exhaust: A review of epidemiologic evidence of cardiac and pulmonary health risks. Environ. Health 2007, 6, 23. [CrossRef]

7. Lane, K.J.; Kangsen Scammell, M.; Levy, J.I.; Fuller, C.H.; Parambi, R.; Zamore, W.; Mwamburi, M.; Brugge, D. Positional error and time-activity patterns in near-highway proximity studies: An exposure misclassification analysis. Environ. Health 2013, 12, 75. [CrossRef] [PubMed]

8. Fuller, C.H.; Brugge, D.; Williams, P.L.; Mittleman, M.A.; Lane, K.; Durant, J.L.; Spengler, J.D. Indoor and outdoor measurements of particle number concentration in near-highway homes. J. Expo. Sci. Environ. Epidemiol. 2013, 23, 506-512. [CrossRef] [PubMed]

9. Cyrys, J.; Pitz, M.; Bischof, W.; Wichmann, H.E.; Heinrich, J. Relationship between indoor and outdoor levels of fine particle mass, particle number concentrations and black smoke under different ventilation conditions. J. Expo. Anal. Environ. Epidemiol. 2004, 14, 275-283. [CrossRef] [PubMed]

10. Patton, A.P.; Zamore, W.; Naumova, E.N.; Levy, J.I.; Brugge, D.; Durant, J.L. Transferability and generalizability of regression models of ultrafine particles in urban neighborhoods in the Boston area. Environ. Sci. Technol. 2015, 49, 6051-6060. [CrossRef]

11. Simon, M.C.; Patton, A.P.; Naumova, E.N.; Levy, J.I.; Kumar, P.; Brugge, D.; Durant, J.L. Combining Measurements from Mobile Monitoring and a Reference Site to Develop Models of Ambient Ultrafine Particle Number Concentration at Residences. Environ. Sci. Technol. 2018, 52, 6985-6995. [CrossRef] 
12. Padro-Martinez, L.T.; Owusu, E.; Reisner, E.; Zamore, W.; Simon, M.C.; Mwamburi, M.; Brown, C.A.; Chung, M.; Brugge, D.; Durant, J.L. A Randomized Cross-over Air Filtration Intervention Trial for Reducing Cardiovascular Health Risks in Residents of Public Housing near a Highway. Int. J. Environ. Res. Public Health 2015, 12, 7814-7838. [CrossRef] [PubMed]

13. Brugge, D.; Simon, M.C.; Hudda, N.; Zellmer, M.; Corlin, L.; Cleland, S.; Lu, E.Y.; Rivera, S.; Byrne, M.; Chung, M.; et al. Lessons from in-home air filtration intervention trials to reduce urban ultrafine particle number concentrations. Build. Environ. 2017, 126, 266-275. [CrossRef] [PubMed]

14. Lane, K.J.; Levy, J.I.; Scammell, M.K.; Patton, A.P.; Durant, J.L.; Mwamburi, M.; Zamore, W.; Brugge, D. Effect of time-activity adjustment on exposure assessment for traffic-related ultrafine particles. J. Expo. Sci. Environ. Epidemiol. 2015, 25, 506-516. [CrossRef]

15. Lane, K.J.; Levy, J.I.; Scammell, M.K.; Peters, J.L.; Patton, A.P.; Reisner, E.; Lowe, L.; Zamore, W.; Durant, J.L.; Brugge, D. Association of modeled long-term personal exposure to ultrafine particles with inflammatory and coagulation biomarkers. Environ. Int. 2016, 92, 173-182. [CrossRef] [PubMed]

16. Wu, C.D.; MacNaughton, P.; Melly, S.; Lane, K.; Adamkiewicz, G.; Durant, J.L.; Brugge, D.; Spengler, J.D. Mapping the vertical distribution of population and particulate air pollution in a near-highway urban neighborhood: Implications for exposure assessment. J. Expo. Sci. Environ. Epidemiol. 2014, 24, 297-304. [CrossRef] [PubMed]

17. Corlin, L.; Woodin, M.; Hart, J.E.; Simon, M.C.; Gute, D.M.; Stowell, J.; Tucker, K.L.; Durant, J.L.; Brugge, D. Longitudinal associations of long-term exposure to ultrafine particles with blood pressure and systemic inflammation in Puerto Rican adults. Environ. Health 2018, 17, 33. [CrossRef] [PubMed]

18. Ohlwein, S.; Hoffmann, B.; Kappeler, R.; Kutlar Joss, M. Health effects of ultrafine particles: Systematic literature search and the potential transferability of the results to the German setting. Umwelt Gesundheit 2018, 5, 1-111.

19. U.S. Environmental Protection Agency. Integrated Science Assessment for Particulate Matter (External Review Draft); EPA: Washington, DC, USA, 2018.

(C) 2019 by the author. Licensee MDPI, Basel, Switzerland. This article is an open access article distributed under the terms and conditions of the Creative Commons Attribution (CC BY) license (http://creativecommons.org/licenses/by/4.0/). 